\title{
Performance of Anaerobic Reactor in Attached and Suspended Growth Mechanisms for the Removal of Tofu Wastewater
}

\author{
R.T. Jullyanti ${ }^{1}$, H. Purnobasuki ${ }^{1}$, T. Nurhariyati ${ }^{1}$, F.N. Rachman ${ }^{1}$, and N.I. Oktavitri ${ }^{1}$
}

\begin{abstract}
This study assessed the removal efficiency of organic compounds in attached and suspended growth mechanisms when an anaerobic reactor was used to treat tofu wastewater. Parameters such as BOD (BiologicalOxygen Demand), TSS (Total Suspended Solid) and VSS (Volatile Suspended Solid) were measured. The assessments of removal efficiency were measuredby the amount of degradation of organic compounds caused by the microorganisms. The analyses were conducted for 14 days with a ratio of $40 \%$ air and $60 \%$ wastewater for the suspended growth mechanism. In attached growth, gravel served as the media at $30 \%$ from $60 \%$ of wastewater with $40 \%$ air. The removal efficiency of organic compounds measured as the decrease of BOD, TSS, and VSS - in suspended and attached growth. BOD in suspended growth decrease 5,55\% while 76,46\% in attached growth, TSS in suspended growth decrease $64,59 \%$ while increased $19,40 \%$ in attached growth, similar results occurred for VSS parameter decrease 2,04\% while increased 31,53\%. The increased result of TSS and VSS in attached growth caused of biofilm growth. In conclusion, BOD, TSS, and VSS decreased greater when the anaerobic treatment in attached growth was applied.
\end{abstract}

Keywords—attached, BOD, removal, suspended, TSS, VSS.

\section{INTRODUCTION}

$\mathrm{R}$ ecently the problem of waste water is very important to be discussed. Because its existence is able to give negative impact for the environment. One of them is tofu wastewater. The tofu wastewater is very often to be spotlight because its potential to pollute the environment, especially for the river area. Potential treatment is really needed to solve this problem. One of them is by using biological processes. The application of biological processes involving microorganisms, with the objective solving of environmental pollution problems, is rapidly growing in recent decades, which wastewater are concerned to. Bioremediation processes, take advantage of microbial degradation of organic and inorganic substances, can be defined as the use of microorganisms to remove environmental pollutants of soils, water and sediments (Pala et al., 2006).

Another way to solve the problem of tofu wastewater is by using anaerobic reactor. The activity growth of microorganisms in the reactor will be monitored based on differences media that are suspended and attached. The media that is used in this research of attached growth is gravel. The desirability to monitor the growth of microorganisms because of its presence that will affect the value of BOD, TSS, and VSS that are used as the reference magnitude of removal capabilities of microorganisms in suspended and attached media. There are some researches based on this topic. One of them "Comparison of Attached Growth Process withSuspended Growth Process" from H. J. Yeon in World Academy of Science, Engineering and Technology 602011 Korea. The result of this research is attached growth process has more possibility for capacity of biomass and nitrogen removal than suspended growth process (Yeon at al, 2011).

${ }^{1}$ R.T. Jullyanti, H. Purnobasuki, T. Nurhariyati, F.N. Rachman, and N.I. Oktavitri are with Department of Environmental Science and Technology, Faculty of Science and Technology, Universitas Airlangga, Surabaya, Indonesia. E-mail: rosvitatrijullyanti@gmail.com; herypurba@yahoo.com; nur_i_d_o@yahoo.com.

\section{MATERIALS AND METHODS}

\section{A. Description of Reactor}

A schematic diagram of the reactor used in this study is shown by Fig. 1. The reactors were tube. The reactor for suspended growth doesn't use media and reactor for attached growth use gravels as the media. The composition of the reactors are $40 \%$ air and $60 \%$ of tofu wastewater in suspended growth and for the attached growth, gravel served as the media at $30 \%$ from $60 \%$ of wastewater with $40 \%$ air. Reactors were designed batch so there are not effluent and influent.

\section{B. Tofu Wastewater}

The tofu wastewater were measured the parameter of BOD, TSS and also VSS of it.

\section{Operating Conditions}

The reactor was operated 14 days for controling the BOD, TSS, and VSS. The analysis was done by day 0 , day 7 , and day 14 to measure the parameter for three times per day. Total volume reactor was $600 \mathrm{ml}$.

\section{RESULT AND DISCUSSION}

The overall results of this study were shown in diagram 1. The removal efficiency of organic compounds measured as the decrease of BOD, TSS, and VSS - in suspended and attached growth. BOD in suspended growth decrease $5,55 \%$ while $76,46 \%$ in attached growth, TSS in suspended growth decrease $64,59 \%$ while icreased $19,40 \%$ in attached growth, similar results occurred for VSS parameter decrease 2,04\% while increased $31,53 \%$. The efficiency was measured from day 0 to day 14 for the time of incubation. The increased result of TSS and VSS in attached growth caused of biofilm growth. The process of removal on day 7 of incubation and 14 better use the attached growth process due to this process are the medium used by the microbes to multiply so the ability of removal is too high.

Based on the graph BOD, TSS , and VSS removal capability is best on day 7 . Because on this day microbes were in accelerated phase so the ability to 
removal is in its maximum. Whereas on day 14 was made possible through a phase of microbial respiration, decreased endogenous so its removal capabilities. Compared to the 3 graphs, the value of TSS and VSS removal on day 14 showed values in the removal of suspended media better than it is because the media attached microorganisms on media attached already experiencing endogenous respiration phase of the microorganisms even have to die so that his ability to decline and lead to higher turbidity. While the BOD values at day 14 showed removal capabilities on the attached better, it is because microorganisms do not require too much dissolved oxygen removal process due to air circulation in the attached.

With batch processing system involves organisms or biochemically active components ( enzyme ) derived from a particular organism.In conclusion, BOD, TSS, and VSS decreased greater when the anaerobic treatment in attached growth was applied

\section{ACKNOWLEDGEMENT}

This research was funded with DIPA Airlangga University 2013. Numbered Letter of Rector Airlangga

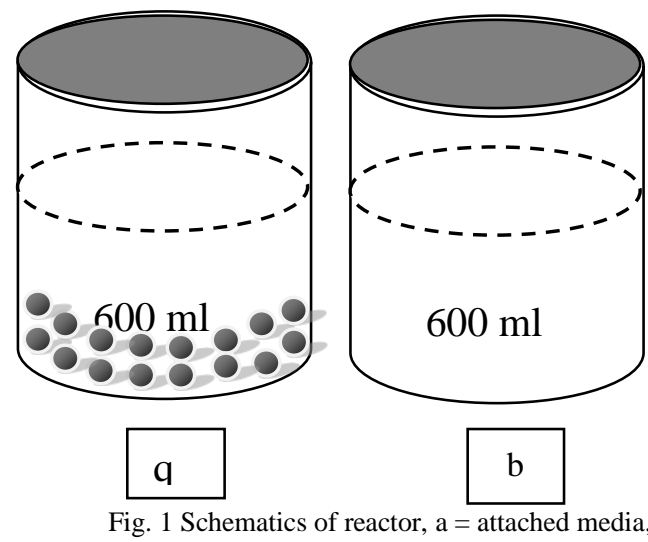
$\mathrm{b}=$ suspended media

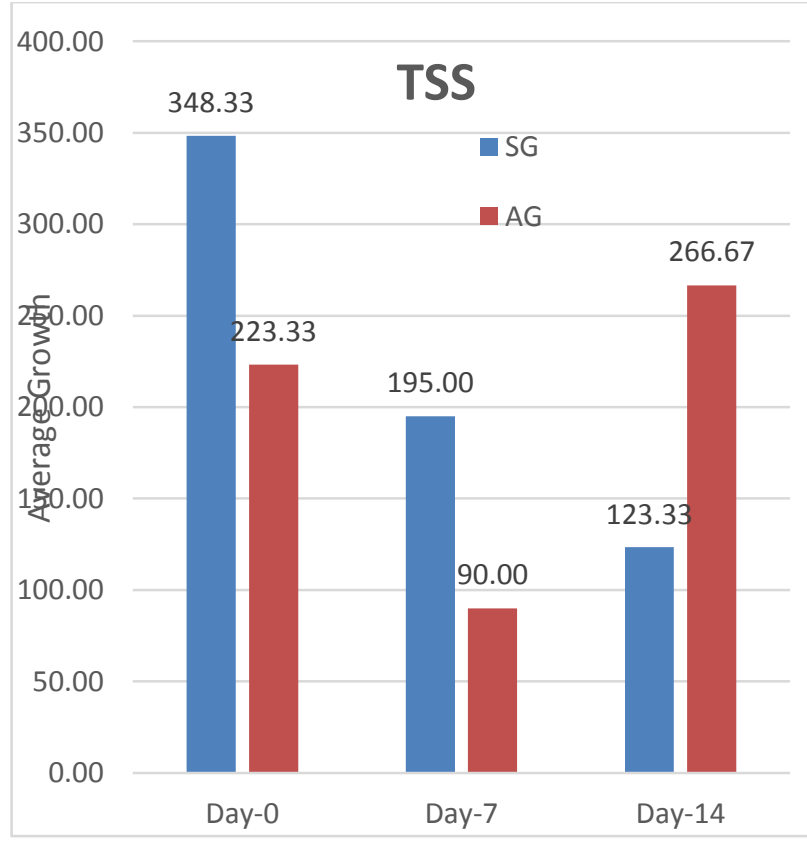

Figure 2. TSS
University 7673/UN3/KR/2013 (2 May 2013).This research was supported with solid team: Deavy Trianingtyas; Bidayatus Saadah; Hairul Amin; Adelia Anju Asmara; Santini Ika R.; Sofiyudin; Defananda.

\section{REFERENCES}

[1]. H. J. Yeon, D. Chang, D. W. Kim, B. K. Kim, J. K. Choi, S. Y. Lim, C. Y. Yoon, D. J. Son, W. Y. Kim. 2011. Comparison of Attached Growth Process with Suspended Growth Process. World Academy of Science, Engineering and Technology 60.

[2]. Hong-Duck Ryu, Sang-Ill Lee. 2005. Comparison of removal characteristics of organic matter, nitrogen and phosphorus between suspended growth and attached-growth biological processes. J. of KSEE. Vol.27, No.2, pp.206-214

[3]. M.Pala, D., De Carvalho, D., Pinto, J.C., Sant Anna Jr, G.L., (2006). "A suitable model to describe bioremediation of a petroleum-contaminated soil". J. Int. Biodeter \& Biodegr., 58( 6): 254-260.

[4]. Metcalf and Eddy. 1991. Wastewater Engineering Treatment and Reuses, Fourth Edition, International Edition, McGraw-Hill, New York. 10

[5]. Metcalf and Eddy, 2003. Waste Water Engineering : Treatment, Disposal, and Reuse. 4th Ed. McGraw Hill Book Co. New York. 550-858.

[6]. Rittmann, B. E., and McCarty, P. L, 2001. Environmental Biotechnology Principles And Applications. McGraw-Hill. , The United States of America.. New York 349-358.

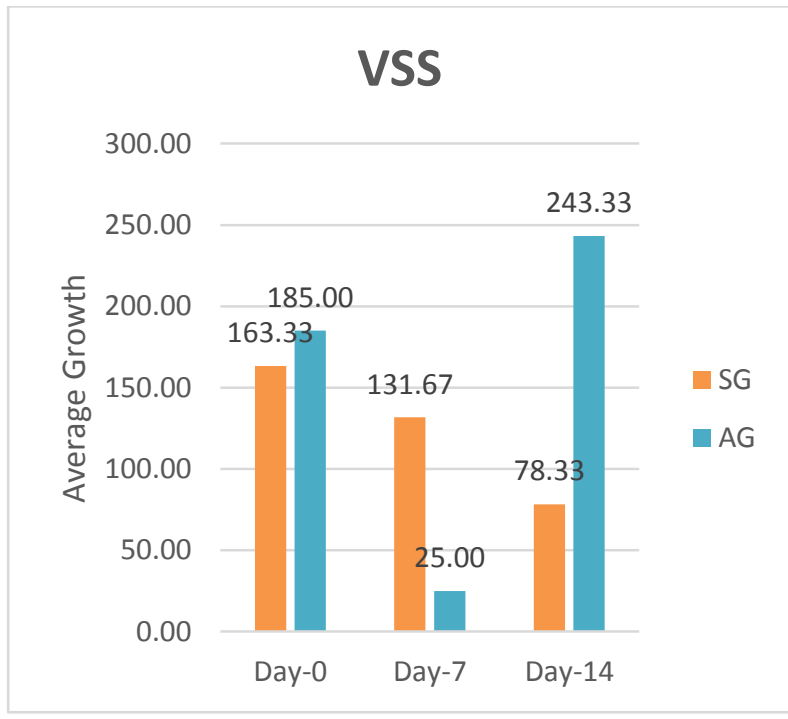

Figure 3. VSS

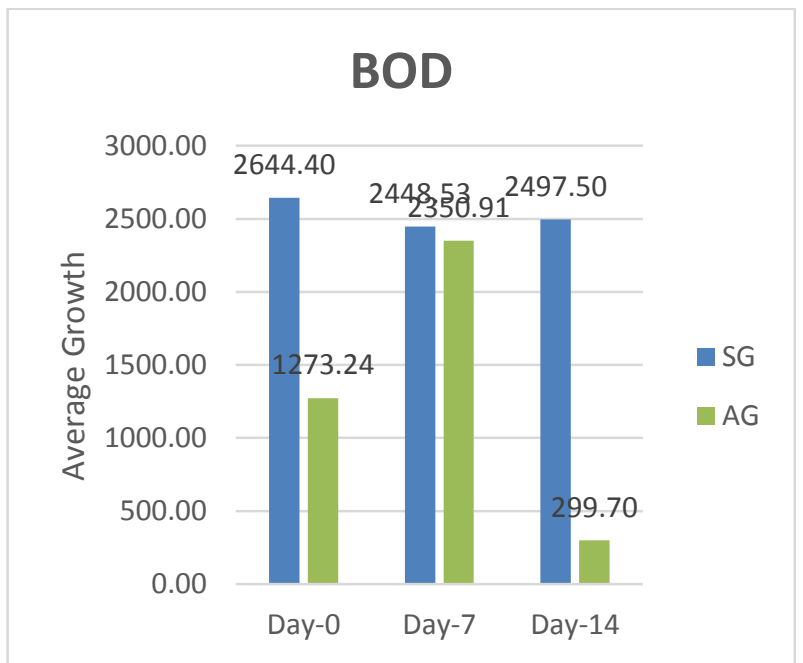

Figure 4. BOD 